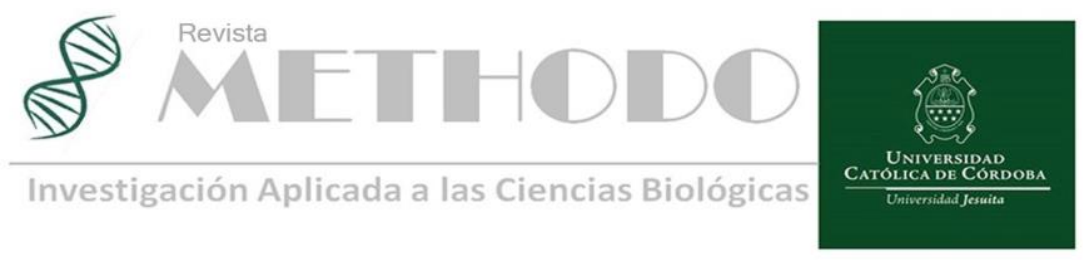

\title{
Estructura de la placenta y su impacto en la transferencia de la inmunidad materno-fetal: revisión en mamíferos domésticos
}

\section{Structure of the placenta and its impact on the transfer of maternal-fetal immunity: a review in domestic mammals}

\author{
Jordana Auad ${ }^{1}$, Julieta Cerutti ${ }^{1}$, Laura G. Cooper ${ }^{1}$, Natalia A. Lozano ${ }^{2}$, Jaime Deltrozzo ${ }^{3}$, Cristina A. \\ Trezza $^{4}$, Marina F. Ponzio ${ }^{5}$, Alejandro Lozano ${ }^{1,2}$. \\ 1. Universidad Católica de Córdoba, Facultad de Ciencias Agropecuarias, Cátedra de Inmunología. \\ 2. Universidad Católica de Córdoba, Facultad de Ciencias de la Salud, Cátedra de Inmunología \\ 3. Universidad Católica de Córdoba, Facultad de Ciencias Agropecuarias, Cátedra de Genética. \\ 4. Universidad Nacional de Córdoba, Facultad de Ciencias Médicas, Hospital Universitario de Maternidad y Neonatología, Servicio de Anatomía \\ Patológica. \\ 5. INICSA-CONICET, Universidad Nacional de Córdoba, Facultad de Ciencias Médicas, Cátedra de Fisiología Humana. \\ Correspondencia: Jordana Auad. Laboratorio de Inmunología y Enfermedades infecciosas, hospital veterinario, Campus Universidad Católica de \\ Córdoba. Av. Armada Argentina 3555 - X5016DHK Córdoba, Argentina. e-mail: jorauad@gmail.com
}

\section{Resumen}

La placenta es un órgano imprescindible para llevar adelante la gestación en mamíferos domésticos. Está constituida por tejidos maternos y fetales y cumple numerosas funciones: intercambio de gases, nutrientes y excreción de productos de desecho, función inmune a nivel de tolerancia y transferencia, función endócrina sintetizando hormonas y factores de crecimiento. Existe una gran diversidad estructural en las placentas de diferentes especies animales. Las clasificaciones de mayor relevancia son la que dependen de la descripción morfológica macroscópica, basada en la distribución de las vellosidades placentarias en el corion del feto y la clasificación histológica, fundamentada en el número de capas que se interponen entre la sangre materna y la fetal, determinando la transferencia de inmunoglobulinas (Igs) a través de este órgano. El objetivo del presente trabajo es describir la estructura placentaria en diferentes especies y su impacto en la transferencia de la inmunidad materno-fetal.

Palabras clave: mamíferos placentarios, feto, inmunoglobulinas, histología comparada.

\begin{abstract}
The placenta is an essential organ for pregnancy in domestic mammals. It is constituted by maternal fetal tissues and fulfills numerous functions: exchange of gases, nutrients and excretion of waste products, prevents the immune system from identifying the embryo as a foreign body and synthesizes hormones and growth factors.

There is great structural diversity in placentas of different animal species, and those can be classified in different ways. The most relevant is the macroscopic morphological classification, which is based on the distribution of the placental villi in the corium of the fetus, and the histological, that relies on the number of layers between maternal and fetal blood, determining if there is immunoglobulin (Ig) transfer or it is
\end{abstract}

Revista Methodo: Investigación Aplicada a las Ciencias Biológicas. Universidad Católica de Córdoba. Jacinto Ríos 571 Bo Gral. Paz. X5004FXS. Córdoba. Argentina. Tel.: (54) 3514517299 / Correo: methodo@ucc.edu.ar / Web: methodo.ucc.edu.ar | ARTICULO DE REVISION Rev. Methodo 2019;4(2):52-6262 
carried out through the colostrum. The objective of the work is to describe the placental structure in different species and its impact on the transfer of maternal-fetal immunity.

Keywords: placental mammals, fetus, immunoglobulins, comparative histological.

\section{Introducción}

En los mamíferos euterios domésticos el crecimiento y la supervivencia del feto durante su desarrollo dependen exclusivamente de la placenta, conformada por tejidos maternos $\mathrm{y}$ fetales ${ }^{1}$.

Aunque la placenta es un órgano temporal, es la interfaz entre la madre y los fetos en desarrollo y constituye un órgano multifacético que realiza una serie de importantes funciones durante la gestación. Estas funciones incluyen el anclaje del feto a la pared uterina, permitir el intercambio de gases y nutrientes entre la madre y el feto, elaborar hormonas y proteger al feto de la respuesta inmune materna, impidiendo que éste sea rechazado como cuerpo extraño, así como también condicionar la transferencia de anticuerpos maternos, entre otras $^{1,2}$. Por lo tanto, la placenta desarrolla funciones respiratorias, nutritivas, excretoras, inmunes y endócrinas mientras los órganos fetales maduran $^{3}$.

En todos los mamíferos placentarios, el establecimiento de un contacto íntimo entre el embrión y la madre sigue una sucesión de pasos críticos comunes, cuya cronología y tiempo pueden variar considerablemente de una especie a otra. Además, estos procesos presentan una gran diversidad basada en la anatomohistología del útero, así como en las interacciones endócrinas y moleculares entre el tejido uterino $y$ el embrionario 4 .

El objetivo del presente trabajo es describir la estructura placentaria en diferentes especies y su impacto en la transferencia de la inmunidad materno-fetal.

\section{Origen}

La fusión de un gameto femenino con uno masculino da lugar a la formación de un cigoto. Tras divisiones repetidas hacia la cavidad uterina se transforma en una vesícula llena de fluido, el blastocisto, con una pared de epitelio simple, el trofoblasto. El blastocisto es nutrido inicialmente por la secreción de las glándulas endometriales. Luego, debido a que las demandas del embrión en desarrollo son cada vez mayores, se hace necesario un mecanismo nutritivo más eficiente, para lo cual se forma un órgano combinado denominado placenta, la cual presenta una estructura bimodal constituida por una porción fetal y otra uterina ${ }^{5}$.
El trofoblasto cambia su función y comienza el desarrollo de membranas extraembrionarias. En la placenta fetal están comprendidos el corion, amnios, alantoides y vestigios de saco vitelino. El corion es la membrana más externa, en contacto con el útero materno, en él se forman las vellosidades coriónicas, a las que llegan los vasos sanguíneos procedentes del alantoides y que penetran más o menos en la mucosa uterina según la especie. El amnios es la membrana más interna, adyacente al feto. El saco alantoideo es un espacio formado por dos capas de alantoides, entre el amnios y el corion (Figura 1). El corioalantoides es el principal componente de la placenta en mamíferos y presenta tres capas celulares de origen fetal: epitelio del corion fetal, tejido mesenquimático fetal y endotelio del capilar fetal $^{4,6}$. Por otro lado, el componente materno de la placenta está dado por la zona más superficial del endometrio uterino y presenta las siguientes capas de tejido: endotelio de los capilares maternos, tejido conectivo materno y epitelio de la mucosa uterina. Existen notables variaciones en relación a la persistencia de las capas de tejido según la especie animal ${ }^{1,4,7}$.

\section{Funciones}

La placenta asume progresiva y temporalmente las funciones eventuales de los pulmones fetales (intercambio gaseoso), del tracto gastrointestinal (absorción de nutrientes) y de los riñones (regulación del volumen del líquido y la eliminación de los metabolitos residuales), mientras estos órganos se desarrollan. También actúa como un órgano endócrino en sí mismo, liberando hormonas esteroideas y peptídicas en ambas circulaciones. La transferencia de una sustancia a través de la barrera materno-fetal depende del espesor y la extensión de la barrera, así como del gradiente de concentración de la sustancia, o la presencia de mecanismos de transferencia activos ${ }^{3}$.

\section{Función de intercambio}

la placenta está destinada al intercambio fisiológico entre la madre y el feto, siendo el intercambio gaseoso la función primordial de este

Revista Methodo: Investigación Aplicada a las Ciencias Biológicas. Universidad Católica de Córdoba. Jacinto Ríos 571 Bo Gral. Paz. X5004FXS. Córdoba. Argentina. Tel.: (54) 3514517299 / Correo: methodo@ucc.edu.ar / Web: methodo.ucc.edu.ar | ARTICULO DE REVISION Rev. Methodo 2019;4(2):52-62 
órgano, seguida por la absorción de nutrientes y la excreción de productos de desecho. Los diferentes componentes de este intercambio son transportados por difusión simple (O2 y CO2), difusión facilitada o mediante transporte activo altamente selectivo ${ }^{1}$. Existe pasaje de la madre al feto de sustancias nutritivas tales como oxígeno, agua, glucosa, lactato, aminoácidos, ácidos grasos libres, vitaminas, electrolitos, hormonas, anticuerpos, así como también algunos medicamentos y patógenos. Del feto a la madre, en cambio, pasan productos finales del metabolismo, tales como urea y anhídrido carbónico ${ }^{1}$.

\section{Función endócrina}

las hormonas placentarias, peptídicas (lactógeno placentario y gonadotrofina coriónica) y esteroidales (progesterona y estrógeno), juegan un papel vital en el establecimiento y mantenimiento de la preñez, la adaptación del organismo materno a ésta, el crecimiento y desarrollo del feto y el mecanismo de parto. Estas hormonas pueden ejercer una acción local actuando en la misma placenta o a distancia a nivel uterino o fetal, variando la secreción y las concentraciones ampliamente de una especie a otra ${ }^{1,4}$.

\section{Función inmune}

es importante destacar que el embrión es un verdadero injerto para la madre (aloinjerto tolerado), ya que posee gran cantidad de proteínas extrañas para el sistema inmune materno, las cuales son sintetizadas a partir de la información genética aportada por el padre. Existe, por lo tanto, un mecanismo compatibilizador que impide el rechazo, dado principalmente por la producción de factores inmunosupresores e inmunomoduladores por parte de la placenta, incluso en estadios tempranos (trofoblasto), y por una adaptación en la respuesta inmune materna frente a los antígenos de histocompatibilidad fetal ${ }^{8}$ Los procesos evolutivos han desarrollado mecanismos muy eficientes de transferencia de inmunidad materna con el objetivo de aportar células inmunes y anticuerpos maternos capaces de proteger al recién nacido temporalmente. La transferencia de anticuerpos puede ocurrir a través de la placenta durante el estadio prenatal, vía calostro y leche materna luego del nacimiento, o por ambas vías según la especie ${ }^{9,13}$.

\section{Clasificación}

Existen múltiples formas de clasificar los tipos de placentas de los mamíferos. Entre las clasificaciones más relevantes se encuentran las fundamentadas en la morfología placentaria y en la estructura histológica de la interfaz materno-fetal.

\section{Clasificación morfológica macroscópica}

se basa en la distribución de las vellosidades placentarias en el saco coriónico que encierra al feto $^{4}$, dependiendo si el área de intercambio materno- fetal se encuentra sobre toda la superficie del saco coriónico o si está restringido a un área en particular ${ }^{2}$.

Difusa:

(porcinos, equinos y camélidos): las vellosidades o pliegues del corion en contacto con el endometrio uterino se distribuyen por toda la superficie de la bolsa coriónica formando pliegues, o fijados sobre toda la superficie del endometrio formando microcotiledones ${ }^{1,4}$. (Figura 2).

Cotiledonaria:

(bovinos, caprinos y ovinos): las vellosidades coriales se agrupan en rosetas llamadas cotiledones que se relacionan con las carúnculas endometriales del útero. Las estructuras uterinas y coriónicas en conjunto conforman una estructura llamada placentoma $^{1}$. Su número varía de acuerdo a la especie animal ${ }^{2,10}$. (Figura 3).

Zonaria:

(caninos y felinos): este tipo de placenta muestra una íntima zona de contacto que forma un cinturón o banda ecuatorial que rodea el saco coriónico ${ }^{2,4}$. (Figura 4).

Discoide:

(primates, roedores y lagomorfos): las vellosidades del corion abarcan un área circular y polarizada presentándose como un disco único (discoide) o doble (bidiscoide) $)^{1,2}$. (Figura 5).

\section{Clasificación histológica}

Se basa en el número de capas que se interponen entre la sangre fetal y la materna. Su número máximo es de seis, tres fetales y tres maternas. Los tejidos maternos son constantes y su número no varía según la especie animal, comprendiendo al epitelio de la mucosa uterina, tejido conectivo materno y endotelio de los capilares maternos ${ }^{4}$. Los tejidos fetales son: epitelio del corion fetal, tejido mesenquimático fetal y endotelio del capilar fetal, existiendo variaciones de acuerdo a la especie involucrada.

En particular, la estructura histológica es una de las más útiles para describir funcionalmente el tipo de placenta desde la perspectiva inmune. Se considera que el número de capas celulares en el área interhemal modifica la permeabilidad placentaria entre la sangre materna y fetal ${ }^{2}$. 
Según la histología se clasifica a las placentas de los mamíferos domésticos de la siguiente manera: Epiteliocorial:

(porcinos, equinos y llamas): seis capas de tejido separan la circulación materna de la fetal durante la gestación ${ }^{4}$. Las vellosidades coriales contactan con el epitelio de la mucosa uterina, existiendo interdigitaciones entre ambos tejidos ${ }^{1}$. Además, las estructuras relacionadas con la placenta, llamadas areolas, se desarrollan en contacto con los orificios de las glándulas uterinas y complementan la capacidad de intercambio metabólico con la madre ${ }^{4,11}$ (Figura 6).

Sinepiteliocorial:

(bovinos, caprinos y ovinos): inicialmente este tipo de placenta se denominó sindesmocorial porque el epitelio uterino parecía haber desaparecido, dejando el trofoblasto en asociación directa con el tejido conectivo endometrial (cinco capas de tejido). Más tarde, se demostró que se forman sincitios entre las células gigantes de trofoblasto bovino, antes denominadas células binucleadas, que emigran y se fusionan con células epiteliales uterinas para formar células híbridas fetomaternales trinucleadas, resultando en la nueva clasificación sinepiteliocorial $^{4,10}$. (Figura 7).

Endoteliocorial:

(caninos y felinos): en este tipo de placenta el corion contacta con el endotelio de los vasos sanguíneos del endometrio, de manera que cuatro capas de tejido separan la sangre materna de la fetal $^{1,4}$. (Figura 8).

Hemocorial:

(primates, roedores y lagomorfos): en este tipo placentario el trofoblasto es más invasivo. Todo el tejido endometrial se erosiona durante la migración de las células del trofoblasto al revestimiento del útero. En la forma final de la placenta, el corion se sumerge directamente en la sangre materna, determinando la presencia de tres capas de tejido entre la circulación materno- fetal $^{4}$ (Figura 9)

\section{Transferencia de inmunidad pasiva}

Cuando nace un mamífero, emerge de un útero estéril hacia un ambiente en el que se expone de inmediato a una multitud de microorganismos. Para sobrevivir, el neonato debe ser capaz de controlar la invasión microbiana en muy poco tiempo. En animales con período gestacional largo (mamíferos domésticos), el sistema inmune alcanza su desarrollo completo al momento del nacimiento, pero la capacidad de responder a los desafíos a patógenos es inefectiva, debido a la falta de estimulación antigénica durante la gestación. Para una respuesta inmune cognitiva, que implica especificidad y memoria, es imprescindible la exposición antigénica que permita la activación de estructuras moleculares para una adecuada inmunidad celular y humoral. La respuesta humoral inicial se denomina primaria, caracterizada por un periodo de latencia prolongado, intensidad baja y duración corta, donde predomina el isotipo de inmunoglobulina $\mathrm{M}$ (IgM) lo que conlleva a una baja afinidad. Por lo tanto, el recién nacido depende de la transferencia de anticuerpos maternos ${ }^{12,13}$. Ésta, puede ocurrir vía placenta en estadio prenatal, vía calostro y leche materna luego del nacimiento, o por ambas vías, según la especie ${ }^{9}$.

En mamíferos el isotipo de Ig predominante a nivel sistémico es la IgG y también es el principal isotipo transferido de la madre a las crías ${ }^{9}$. Los mecanismos de transferencia pueden ser dependientes de la expresión del receptor neonatal Fc (FcRn) que permite el transporte activo de IgG o bien, de un proceso no selectivo de captación de macromoléculas a través de vacuolas de transporte ${ }^{13,14}$. El transporte mediado por el receptor FcRn depende del gradiente de $\mathrm{pH}$, uniéndose la $\mathrm{IgG}$ a $\mathrm{pH}$ ácido y siendo liberada a pH neutro; esto garantiza la unión a tipos celulares específicos (placenta, glándula mamaria, enterocitos duodenales) y la liberación de $\mathrm{IgG}$ en sitios adecuados como el torrente sanguíneo ${ }^{9,13}$.

(Figura 10)

En animales que presentan placentación hemocorial (primates) toda la IgG se transfiere a través de la placenta durante la vida fetal debido a la expresión del FcRn en este tejido. En roedores (ratones y ratas), la $\mathrm{IgG}$ maternal se transfiere además por la ingesta de calostro y leche materna, evidenciándose la presencia de este receptor en glándula mamaria e intestino delgado $9,14,16$.

En perros y gatos (placenta endoteliocorial), la transferencia de IgG ocurre por mecanismos pre y posnatales. Entre el 5 y $10 \%$ se transfieren antes del nacimiento y luego vía calostro y leche materna, a través de mecanismos independientes del receptor ${ }^{9,14}$.

La estructura compleja de la placenta y la falta de expresión del FcRn en este tejido, determina que el transporte de Igs en rumiantes (placenta sinepiteliocorial), al igual que en equinos y porcinos (placenta epiteliocorial) se realice exclusivamente a través de la ingesta de calostro. El feto no recibe anticuerpos maternos vía placenta, y las crías nacen agammaglobulinémicas. La adquisición de Igs se produce por la ingesta de calostro durante las primeras horas de vida. La IgG es transportada no selectivamente del intestino a la circulación general, no se detecta expresión del receptor FcRn en los enterocitos del recién nacido y la captación de macromoléculas se realiza por vacuolas de transporte ${ }^{14}$.

Revista Methodo: Investigación Aplicada a las Ciencias Biológicas. Universidad Católica de Córdoba. Jacinto Ríos 571 Bo Gral. Paz. X5004FXS. Córdoba. Argentina. Tel.: (54) 3514517299 / Correo: methodo@ucc.edu.ar / Web: methodo.ucc.edu.ar | ARTICULO DE REVISION Rev. Methodo 2019;4(2):52-62 
Independiente de la especie y del mecanismo de absorción de Igs, ésta es máxima 6 a 8 horas después del nacimiento y disminuye progresivamente para hacerse nula a partir de las 24 a 36 horas postparto ${ }^{17}$. A partir de este momento, las Igs ingeridas en leche sólo actúan localmente en la luz intestinal ${ }^{9}$.

$\mathrm{Si}$ bien las Igs calostrales son las principales moléculas asociadas con la protección a las infecciones, existen otros componentes bioactivos como factores de crecimiento, moléculas con actividad antimicrobiana y citoquinas que modulan la respuesta inmune y protegen a los neonatos durante las primeras semanas de vida ${ }^{9}$.

\section{Conclusión}

La placenta es un órgano fundamental en el desarrollo prenatal de las crías de los mamíferos, ya que cumple diversas funciones vitales, entre ellas la regulación y composición del sistema inmune. La estructura placentaria es variable según la especie pudiendo identificarse 4 tipos de placentas que se diferencian tanto a nivel morfológico como histológico. La histología del tejido placentario define la capacidad de permitir el pasaje de macromoléculas como la IgG en el periodo prenatal.

La placenta hemocorial juega un rol fundamental en la transferencia pasiva de $\operatorname{IgG}$ de la madre al feto, en tanto que la placenta endoteliocorial sólo permite que una pequeña proporción de esta inmunoglobulina se transfiera a los fetos, siendo muy importante el correcto calostrado de las crías. La estructura histológica de las placentas de tipo epiteliocorial y sinepiteliocorial no permiten el pasaje de IgG en el periodo prenatal, por lo que las crías dependen exclusivamente de la adquisición de IgG a partir del calostro materno.

\section{Agradecimientos}

A las Méd. Vet. Betiana B. Tscherig y Med. Paula Robredo por la obtención de imágenes digitales de macroscopía de placentas equina y humana respectivamente; a la Dra. Kristi Baker por su colaboración en la elaboración de la inmunohistoquímica del receptor FcRn.

\section{Bibliografía}

1. Roa I, Smok S C, Prieto G R. Placenta: Anatomía e Histología Comparada. Int J Morphol. 2012;30(4):1490-1496.

2. Furukawa S, Kuroda Y, Sugiyama A. A comparison of the histological structure of the placenta in experimental animals. J Toxicol Pathol. 2014;27(1):11-18.

3. Donnelly L, Campling G. Functions of the placenta. Anaesth Intensive Care Med. 2014;15(3):124-127.

4. Chavatte-Palmer P, Tarrade A. Placentation in different mammalian species. Ann Endocrinol (Paris). 2016;77(2):67-74.

5. Dantzer V, Bjorkman N. Capítulo 14. Placentación. En: Histología veterinaria. Segunda edición. Editorial Acribia, Zaragoza; 1994: 291-301.

6. Coy Fuster P. Capítulo 64. Fisiología de la gestación. En: García Sacristán A et al, Fisiología veterinaria. Primera edición. Madrid. Interamericana McGraw-Hill Editorial; 1995: 861-874.

7. Noden DM, de Lahunta A. Capítulo 3. Membranas extraembrionarias y placentación. En: Noden DM et al, Embriología de los animales dométicos. Primera edición. Zaragoza. Editorial Acribia; 1990: 53-76.

8. Moffett A, Loke C. Immunology of placentation in eutherian mammals. Nat Rev Immunol. 2006;6(8):584-594.

9. Parreño V, Saif LJ. Capítulo 3. Inmunidad pasiva. En: Schudel AA,. Vacunación en la prevención, el control y la erradicación de las enfermedades infecciosas de los animales. Primera edición. Editor Schudel AA. Buenos Aires; 2017. p. 47-64.

10. Haeger JD, Hambruch N, Pfarrer C. The bovine placenta in vivo and in vitro. Theriogenology. 2016;1-7.

11. Iturrizaga DM, Verechia FT, Santos TC, Bombonato PP, et al. The materno -fetal inter face in llama (Lama guanicoe glama). Pesqui Vet Bras. 2007;27(6):221-228.

12. Iturrizaga DM, Verechia FT, Santos TC, Bombonato PP, et al. The materno -fetal inter face in llama (Lama guanicoe glama). Pesqui Vet Bras. 2007;27(6):221-228.

13. Lozano NA, Lozano A, Marini V, Saranz RJ, et al. Expression of FcRn receptor in placental tissue and its relationship with IgG levels in term and preterm newborns. Am J Reprod Immunol. 2018;80(3):1-7.

14. Baintner K. Transmission of antibodies from mother to young: Evolutionary strategies in a proteolytic environment. Vet Immunol Immunopathol. 2007; 117:153-161. 
15. Roopenian DC, Akilesh S. FcRn: the neonatal Fc receptor comes of age. Nature. 2007;7:715-724.

16. Raghavan M, Bonagura VR, Morrison SL, Bjorkman PJ. Analysis of the $\mathrm{pH}$ dependence of the Neonatal Fc Receptor/Inmunoglobulina G Interaction Using Antibody and Receptor Variants. Biochemistry. 1995;34(45):1464914657.
17. Cooper LG, Auad J, Cerutti J, Lozano A, et al. Dinámica de la transferencia de inmunoglobulina $\mathrm{G}$ en el binomio madre-cría de la especie caprina. Rev Vet. 2014;25(2):105-108.

\section{ANEXO DE FIGURAS}

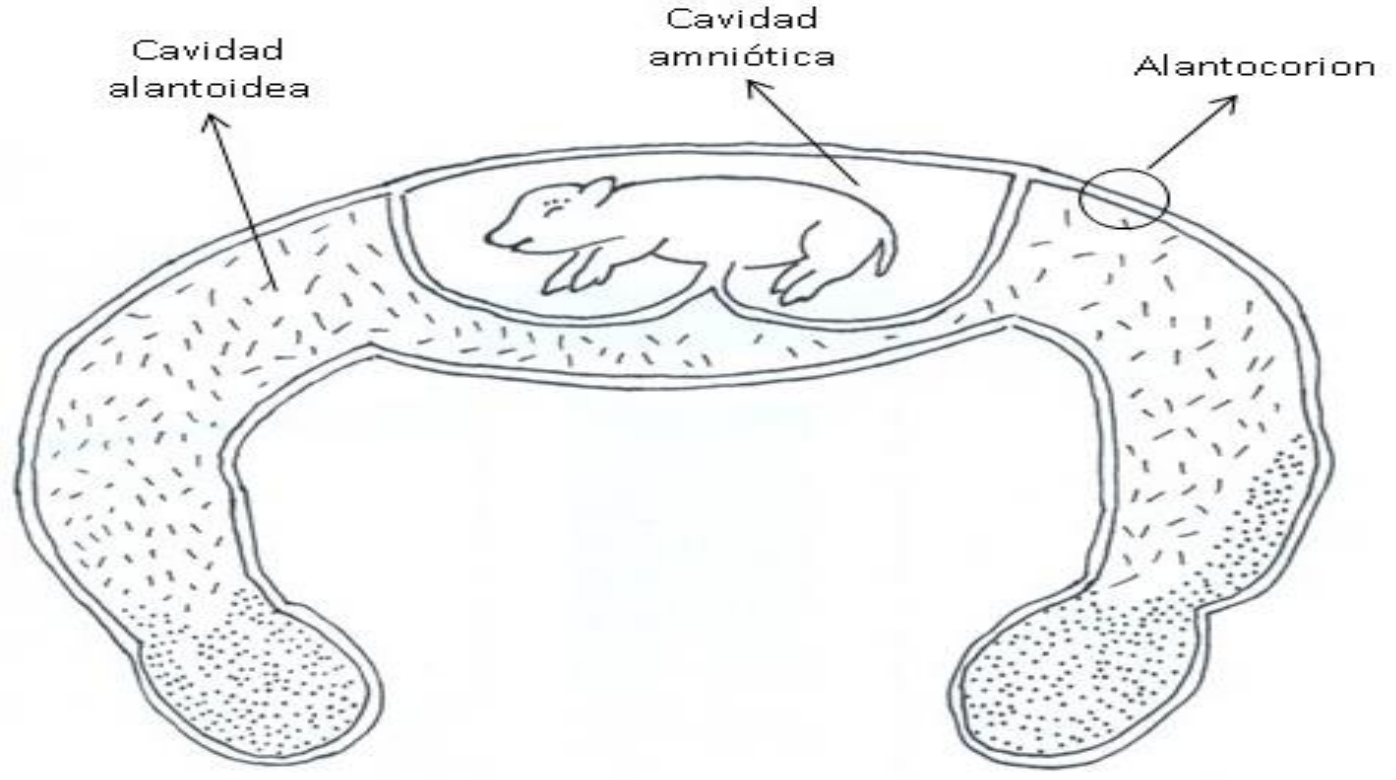

Figura 1: Esquema de membranas extraembrionarias de la placenta, tomando como modelo placenta y feto porcino (modificado de Roa, 2012).

Revista Methodo: Investigación Aplicada a las Ciencias Biológicas. Universidad Católica de Córdoba. Jacinto Ríos 571 Bo Gral. Paz. X5004FXS. Córdoba. Argentina. Tel.: (54) 3514517299 / Correo: methodo@ucc.edu.ar / Web: methodo.ucc.edu.ar | ARTICULO DE REVISION Rev. Methodo 2019;4(2):52-62 
A

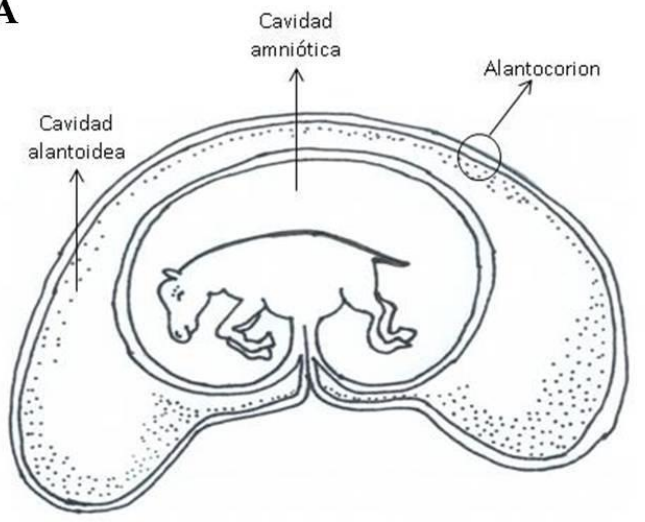

B

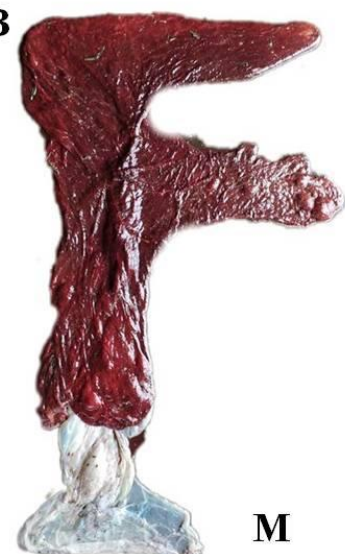

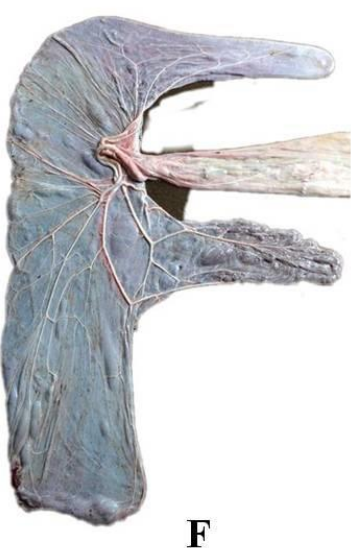

Figura 2: A) Esquema de las envolturas fetales de la placenta difusa (modificado de Dantzer, 1994). B) Imagen digital de la macroscopía de la placenta de equino: cara materna $(\mathrm{M})$ y cara fetal $(\mathrm{F})$.

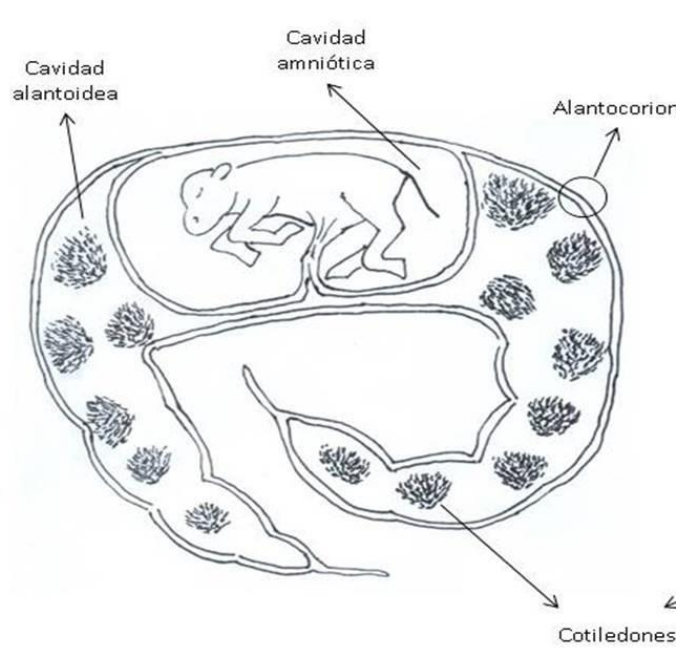

A

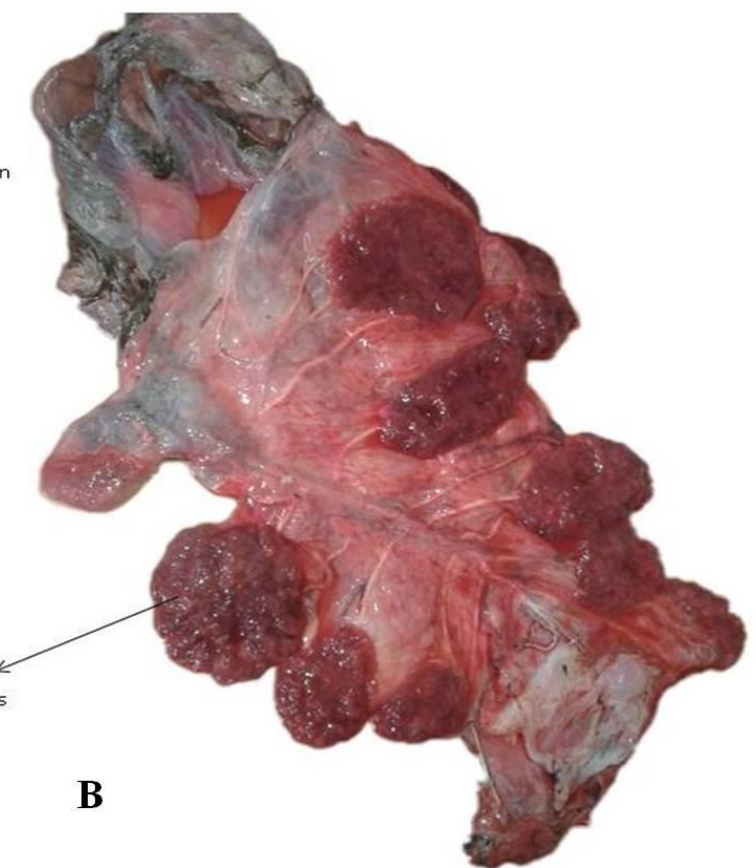

Figura 3: A) Esquema de las envolturas fetales de placenta cotiledonaria (modificado de Dantzer, 1994). B) Imagen digital de la macroscopía de la placenta cotiledonaria de cabra.

Revista Methodo: Investigación Aplicada a las Ciencias Biológicas. Universidad Católica de Córdoba. Jacinto Ríos 571 Bo Gral. Paz. X5004FXS. Córdoba. Argentina. Tel.: (54) 3514517299 / Correo: methodo@ucc.edu.ar / Web: methodo.ucc.edu.ar | ARTICULO DE REVISION Rev. Methodo 2019;4(2):52-62 


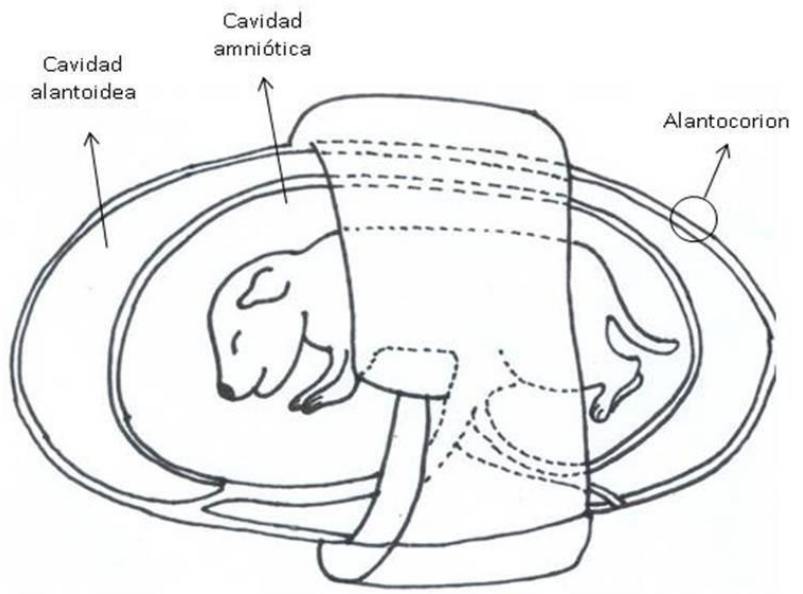

A

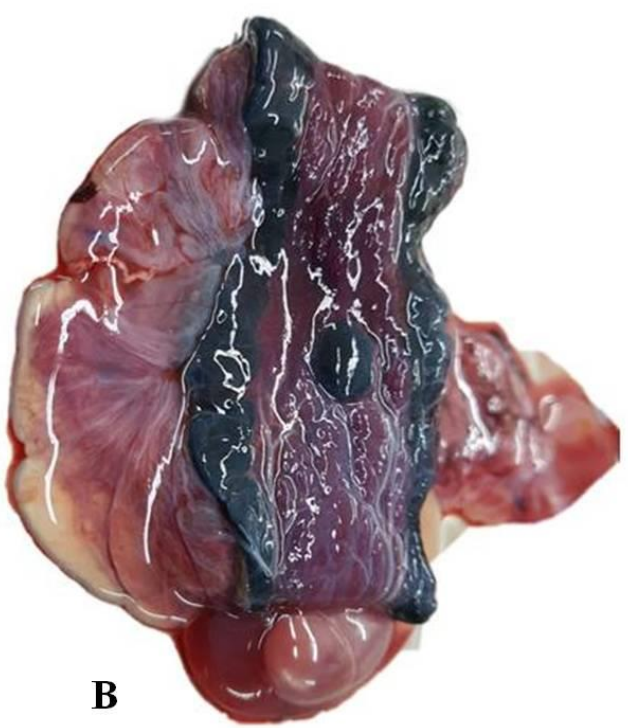

Figura 4: A) Esquema de las envolturas fetales de placenta zonaria (modificado de Dantzer, 1994). B) Imagen digital de la macroscopía de la placenta zonaria de canino.

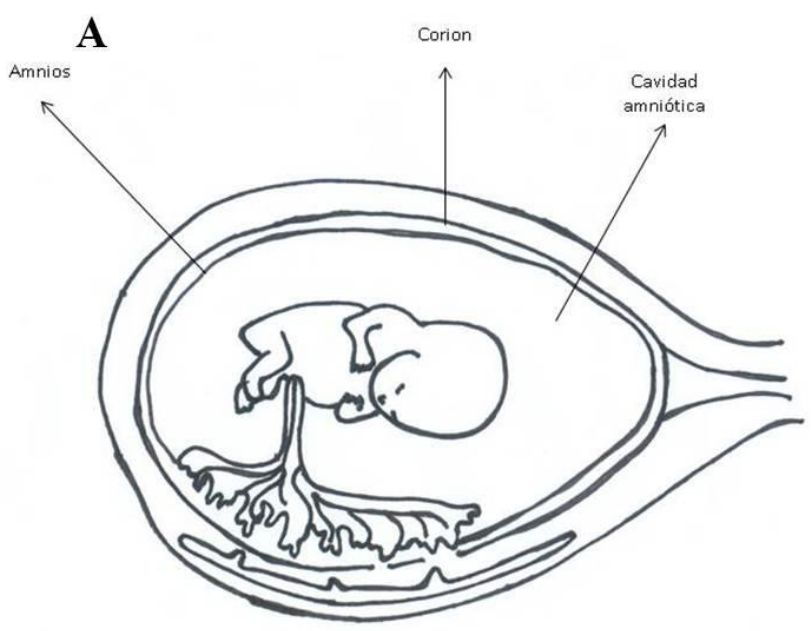

B

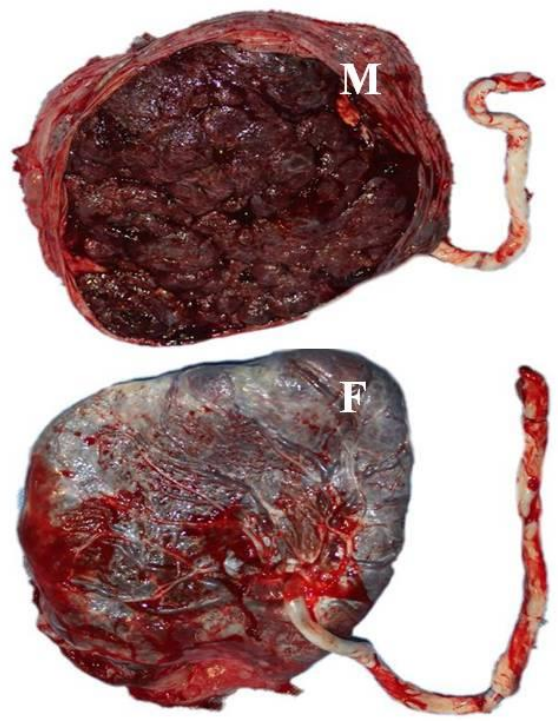

Figura 5: A) Esquema de las envolturas fetales de la placenta discoide de humano (modificado de Moffett, 2006). B) Imagen digital de macroscopía de la placenta discoide de humano: cara materna $(\mathrm{M})$ y cara fetal $(\mathrm{F})$.

Revista Methodo: Investigación Aplicada a las Ciencias Biológicas. Universidad Católica de Córdoba. Jacinto Ríos 571 Bo Gral. Paz. X5004FXS. Córdoba. Argentina. Tel.: (54) 3514517299 / Correo: methodo@ucc.edu.ar / Web: methodo.ucc.edu.ar | ARTICULO DE REVISION Rev. Methodo 2019;4(2):52-62 
B

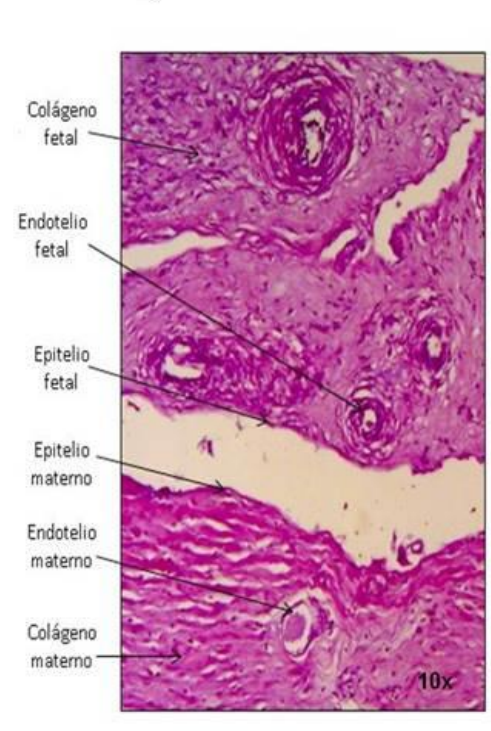

A

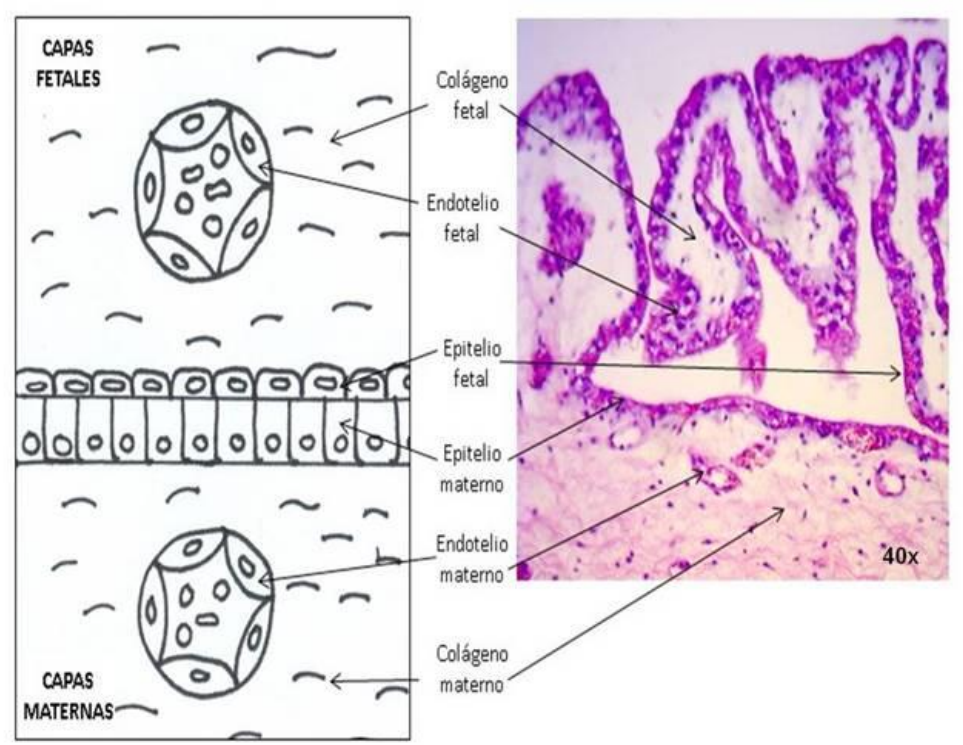

Figura 6: Esquema de la placenta epiteliocorial (A) (modificado de Moffett, 2006) e imagen histológica de la placenta epiteliocorial de equino (B) y llama (C). Coloración hematoxilina eosina.

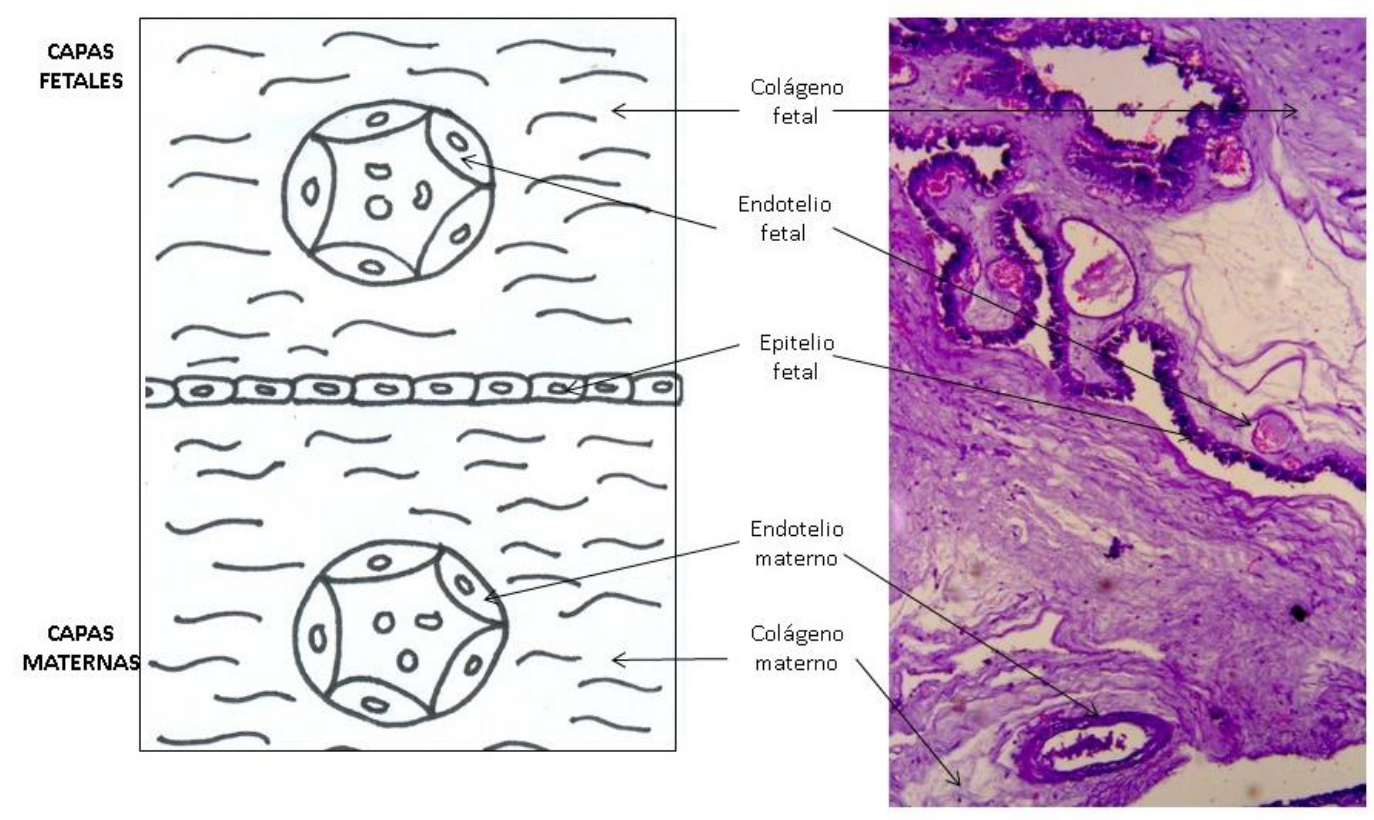

Figura 7: Esquema de la placenta sinepiteliocorial (modificado de Moffett, 2006) e imagen histológica de la placenta sinepiteliocorial de bovino. Coloración hematoxilina eosina (10X).

Revista Methodo: Investigación Aplicada a las Ciencias Biológicas. Universidad Católica de Córdoba Jacinto Ríos 571 Bo Gral. Paz. X5004FXS. Córdoba. Argentina. Tel.: (54) 3514517299 / Correo: methodo@ucc.edu.ar / Web: methodo.ucc.edu.ar | ARTICULO DE REVISION Rev. Methodo 2019;4(2):52-62 


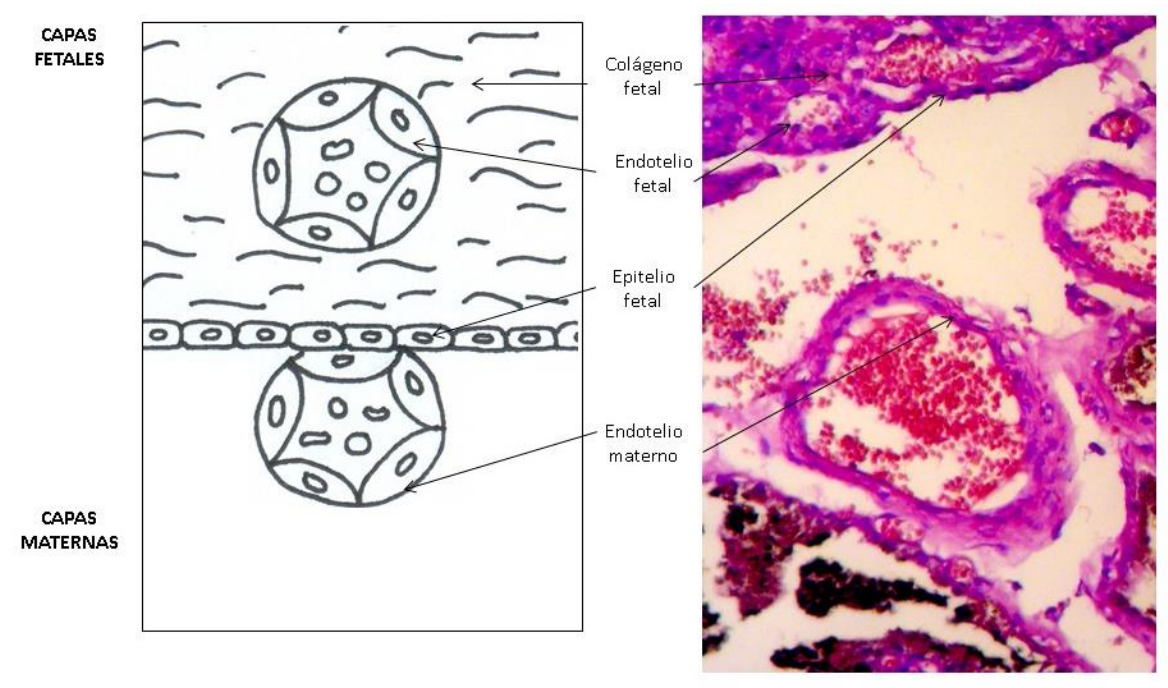

Figura 8: Esquema de la placenta endoteliocorial (modificado de Moffett, 2006) e imagen histológica de la placenta endoteliocorial de canino. Coloración hematoxilina eosina (40X).

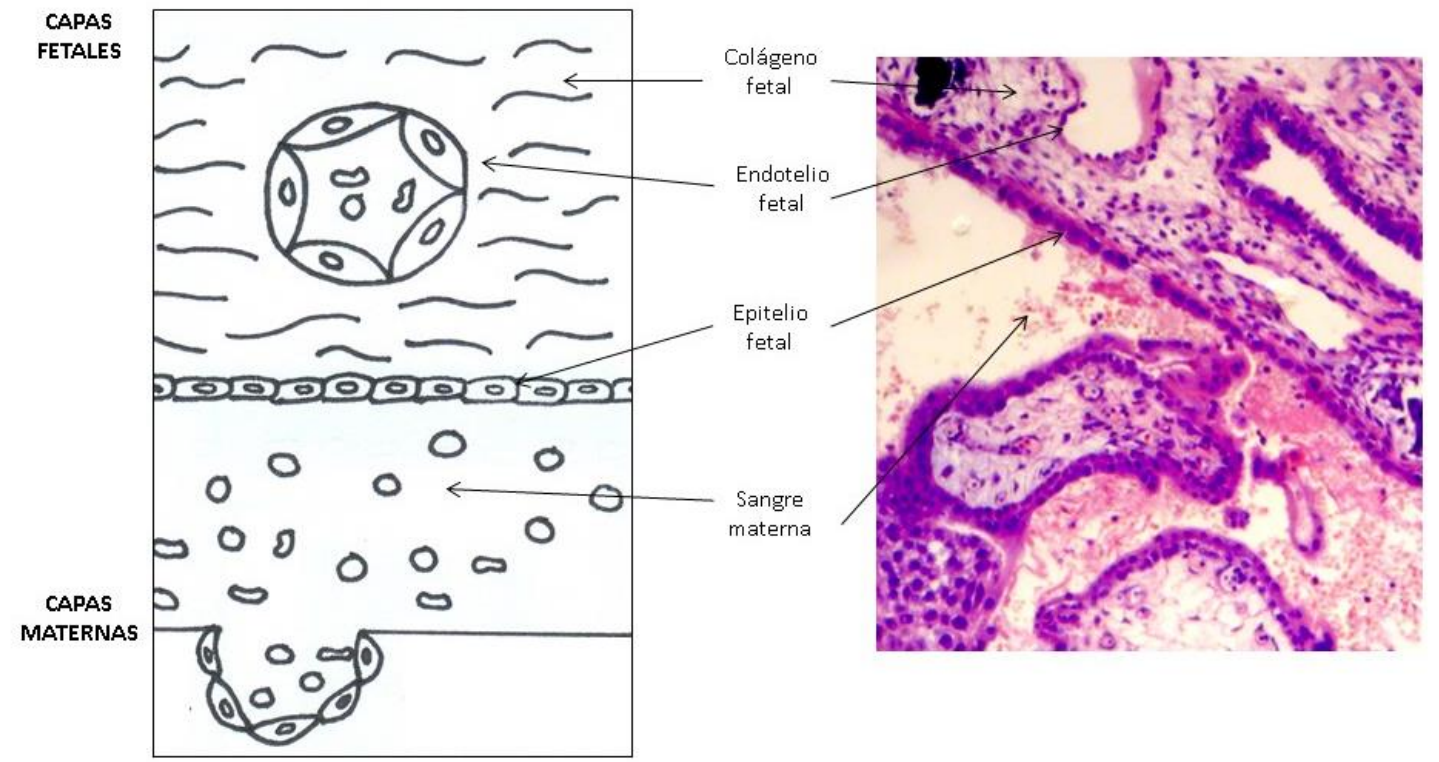

Figura 9: Esquema de la placenta hemocorial (modificado de Moffett, 2006) e imagen histológica de la placenta hemocorial de ratón. Coloración hematoxilina eosina (10X).

Revista Methodo: Investigación Aplicada a las Ciencias Biológicas. Universidad Católica de Córdoba. Jacinto Ríos 571 Bo Gral. Paz. X5004FXS. Córdoba. Argentina. Tel.: (54) 3514517299 / Correo: methodo@ucc.edu.ar / Web: methodo.ucc.edu.ar | ARTICULO DE REVISION Rev. Methodo 2019;4(2):52-62 


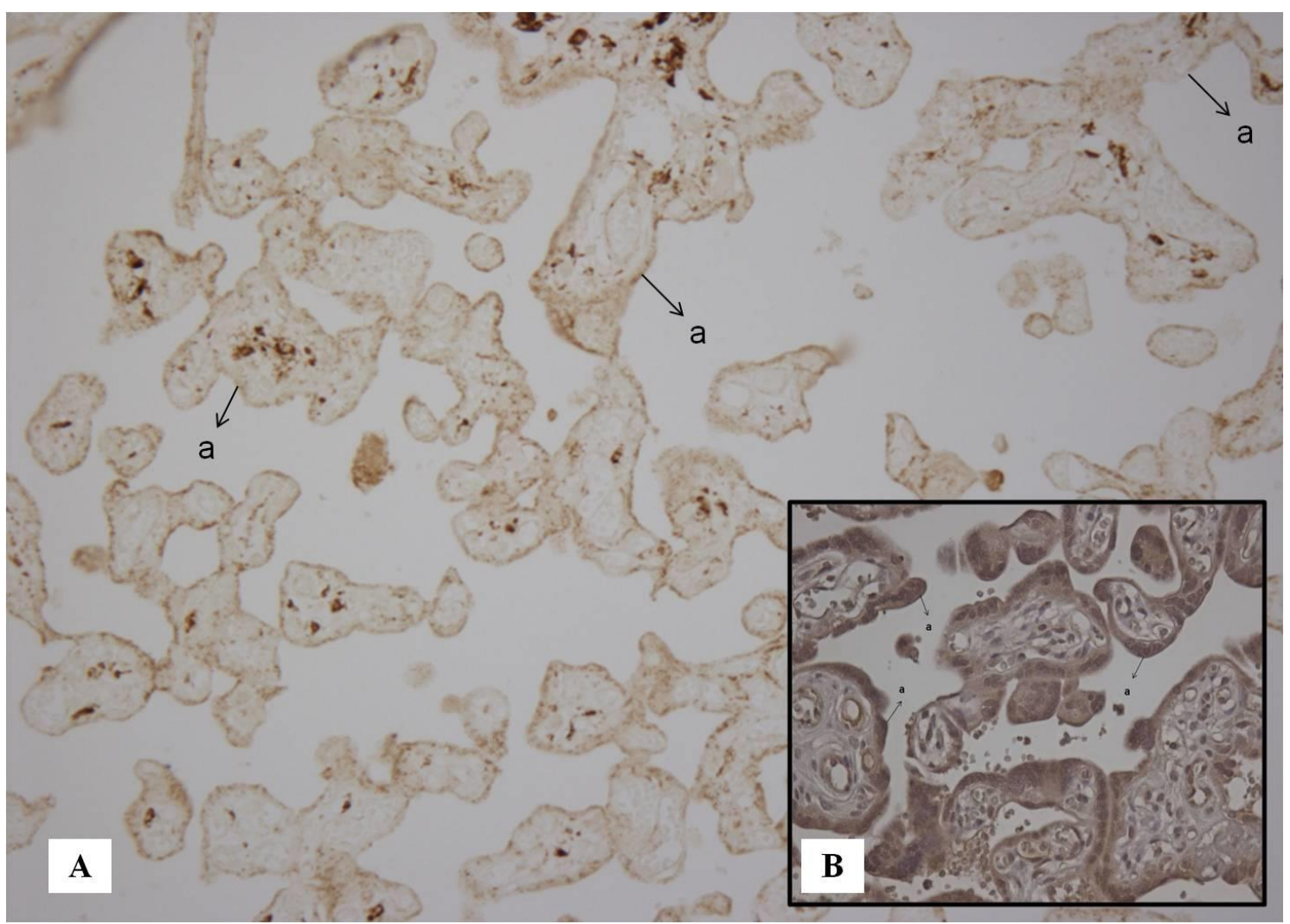

Figura 10: Inmunohistoquímica del receptor FcRn en placenta humana (a). Tejido placentario humano de recién nacido a término con tinción de hematoxilina eosina e inmunohistoquímica para FcRn con diaminobencidina (DAB). A) (20X) y B) (40X).

\section{(c) (1)(0)}

Revista Methodo: Investigación Aplicada a las Ciencias Biológicas. Universidad Católica de Córdoba. Jacinto Ríos 571 Bo Gral. Paz. X5004FXS. Córdoba. Argentina. Tel.: (54) 3514517299 / Correo: methodo@ucc.edu.ar / Web: methodo.ucc.edu.ar | ARTICULO DE REVISION Rev. Methodo 2019;4(2):52-62 